\begin{tabular}{c} 
Volume and Issues Obtainable at Center for Sustainability Research and Consultancy \\
Journal of Business and Social Review in Emerging Economies \\
ISSN: 2519-089X (E): 2519-0326 \\
Volume 6: No. 4, December 2020 \\
CSRC \\
Journal homepage: www.publishing.globalcsrc.org/jbsee \\
\hline
\end{tabular}

\title{
The Impact of Economic Growth, Foreign Direct Investment, Urbanization, Fossils Fuel Consumption on Environmental Degradation in Emerging Asian Economies
}

\author{
${ }^{1}$ Muhammad Waqas Ashraf, ${ }^{2}$ Hafeez ur Rehman, Imran Sharif Chaudhry \\ ${ }^{1} \mathrm{PhD}$ Scholar, Department of Economics, University of Management and Technology Lahore, Pakistan, \\ mianwaqqasashraf@gmail.com \\ ${ }^{2}$ Chairman, Department of Economics, University of Management and Technology Lahore-Pakistan, \\ hafeez.rehman@umt.edu.pk \\ ${ }^{3}$ Director, School of Economics, Bahauddin Zakariya University Multan, Pakistan, imran@ bzu.edu.pk
}

\begin{tabular}{l}
\hline ARTICLE DETAILS \\
\hline History \\
Revised format: November \\
2020 \\
Available Online: December \\
2020
\end{tabular}

Keywords

Environmental Kuznut Curve

(EKC), Carbon dioxide

emissions, Fossil fuel,

Urbanization, Environmental

Degradation

\section{JEL Classification}

M2, M21
ABSTRACT

The current examination ascertains the impact of foreign direct investment, urbanization, economic growth, fossil fuel consumption on carbon emissions in eleven rising Asian economies. Panel data has been scrutinized from 1990 to 2018, and (ARDL)/PMG model is executed. The outcomes of the model exemplify that in these growing Asian economies, the triumph to cultivate economic growth, foreign direct investment, urbanization and fossil fuels are bestowing $\mathrm{CO} 2$ emissions and deteriorating the environmental circumstances at the regional level. Moreover, the conclusions emphasis that foreign direct investment is a source of environmental humiliation and increases carbon emissions at the regional level. Furthermore, outcomes of the investigate also confirms the existence of (EKC) in these eleven emerging Asian economies. The study also suggest that by lessening the consumption of fossil fuel energy and encouragement of an environmental responsive economic growth policy will be suitable for the affluence in these emerging developing Asian economies and also the rest of world..

(C) 2020 Center for Sustainability Research and Consultancy Pakistan under a Creative Commons Attribution-NonCommercial-ShareAlike

4.0

Corresponding author's email address: hafeez.rehman@umt.edu.pk

Recommended citation: Ashraf, M. W., Rehman, H. \& Chaudhry, I. S. (2020). The Impact of Economic Growth, Foreign Direct Investment, Urbanization, Fossils Fuel Consumption on Environmental Degradation in Emerging Asian Economies. Journal of Business and Social Review in Emerging Economies, 6(4), 1479-1495

\section{Introduction}

Among other challenges, most important tasks in the world is environmental degradation. Basically with the passage of time, increase in economic activities and economic growth leads to generate economic degradation (Perman et al., 2003). There are so many factors, which are responsible for environmental degradation and creates pollution by carbon dioxide emissions (Jacobson, 2008). Economic activity is the key factor of environmental disrepair. In other words, swift economic development and additional 
production in these emerging economies have to bear the overheads of environmental degradation (Shehbaz et al., 2016). Economic growth intended to change the global climate, predominantly through use of fossil fuel (non-renewable) resources. Eeconomic activity was one of the key factors for the increase in global warming in the middle of the 20th century in these Asian economies (IPCC 2018). The consumption of energy was low in Asian economies in 1960,s but the economic reforms and sprawling of urban population in late 1970,s and in 1980,s enhance the use of energy in this region.These factors increase the environmental degradation in this region and the rest of the world (Guttikunda et al, 2003). With augmented carbon emissions from the households, the threat of toxicities such as pneumonia and other breathing deseases increased (Hanif 2018b). In addition, the volume of ejection comprises anthropogenic factors (for example urbanisation, FDI, population size and per capita GDP). Amplified carbon dioxide evacuation donates to a variety of diseases, including cardiovascular and respiratory complaints (WHO 2016). Social and economic actions are esteemed, which decline the stability of heat and energy exchanges over the Globe. The mesosphere of the universe has changed environment, which is often categorized as "global warming." Humanistic activities have contributed to intensified atmospheric carbon dioxide $\left(\mathrm{CO}_{2}\right)$, predominantly by the energy usage specially for production targets (Maranga et al. 2010). There have not been reliable and consistent outcomes from earlier studies on environmental degradation, urbanization and carbon emissions at regional level. Thus, further work is required. The outcomes of a region or a sole country can not be revealed globally because of multifaceted geographical and socio-economic circumstances. Here, we will investigate the effect of economic growth, urbanization, FDI, fossil fuel consumption on carbon emissions/emanations in Asian emerging countries. Sprinkling literature on carbon emissions and environmental degradation in different regions has dazed the effect of economic growth, including Apergis and Ozturk (2015), Wang et al. ( 2016), Nasreen et al. (2017). Empirical evidence is uncertain, especially as regard of successful policy suggestions in the emerging economies of Asia. So present study has a remarkable association between the urbanization, fossil fuel energy, GDP and $\mathrm{CO}_{2}$ emanations/emissions.

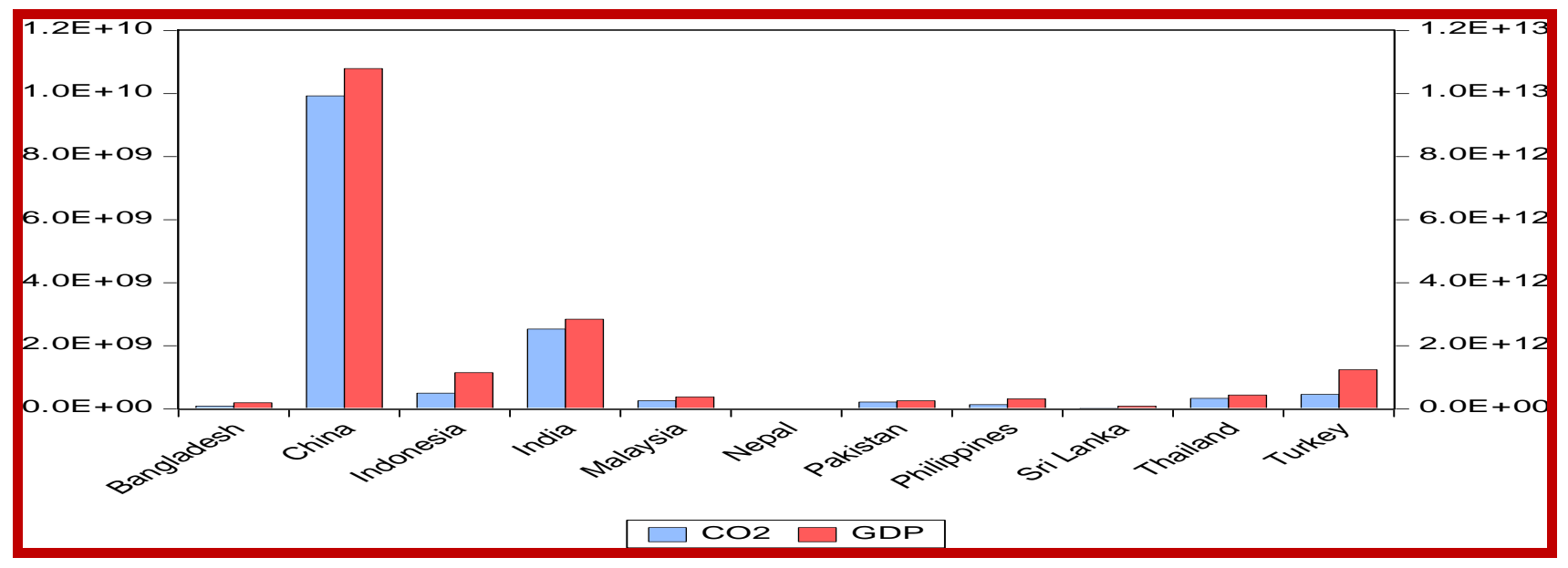

The economic growth trend in emerging but less developed countries in 2018 shows that nonlinear trend. The china has the largest share of GDP which was 10797222227694.5. The second highest GDP was 68358370 in India. The third one followed by Indonesia which was 1146844815417 . The graphical explanation also shows that in 2018 the emission of $\mathrm{CO}_{2}$ of these Countries, the highest carbon dioxide emitter was Malaysia (254368367.421025 million ton), on second level China (9928444878.45 million ton) and lowest level is Nepal (9178807.276219 million ton) on third level, respectively. These data showed that in 2018 China the top economic growth with highest carbon dioxide emitter. 


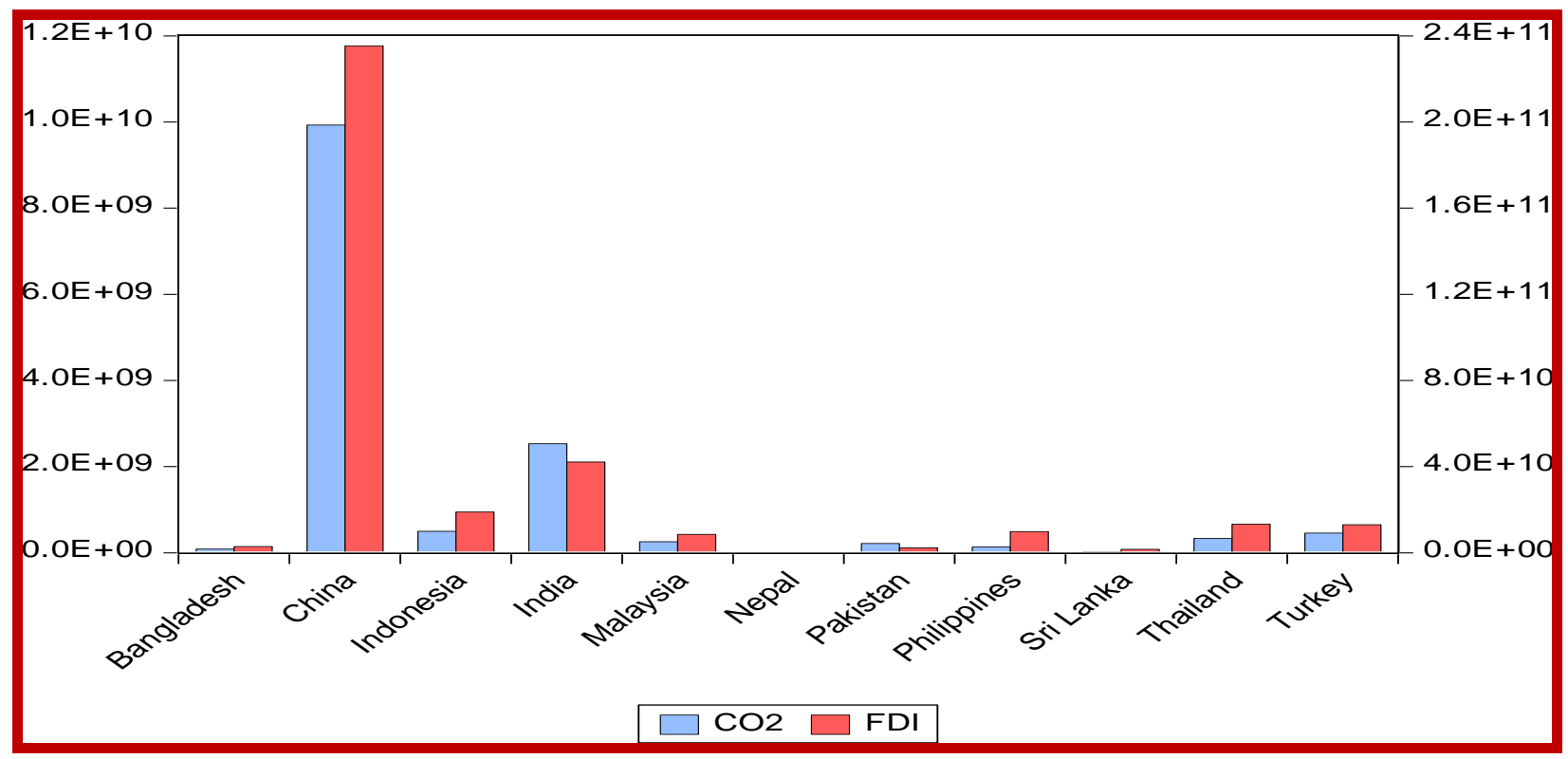

The FDI trend in emerging but less developed countries in 2018 shows that nonlinear trend. The China has the largest share of FDI which was 235365050036.341. The second highest FDI was 42117450737.2644 in India. The third one followed by Indonesia which was 18909826043.5105.

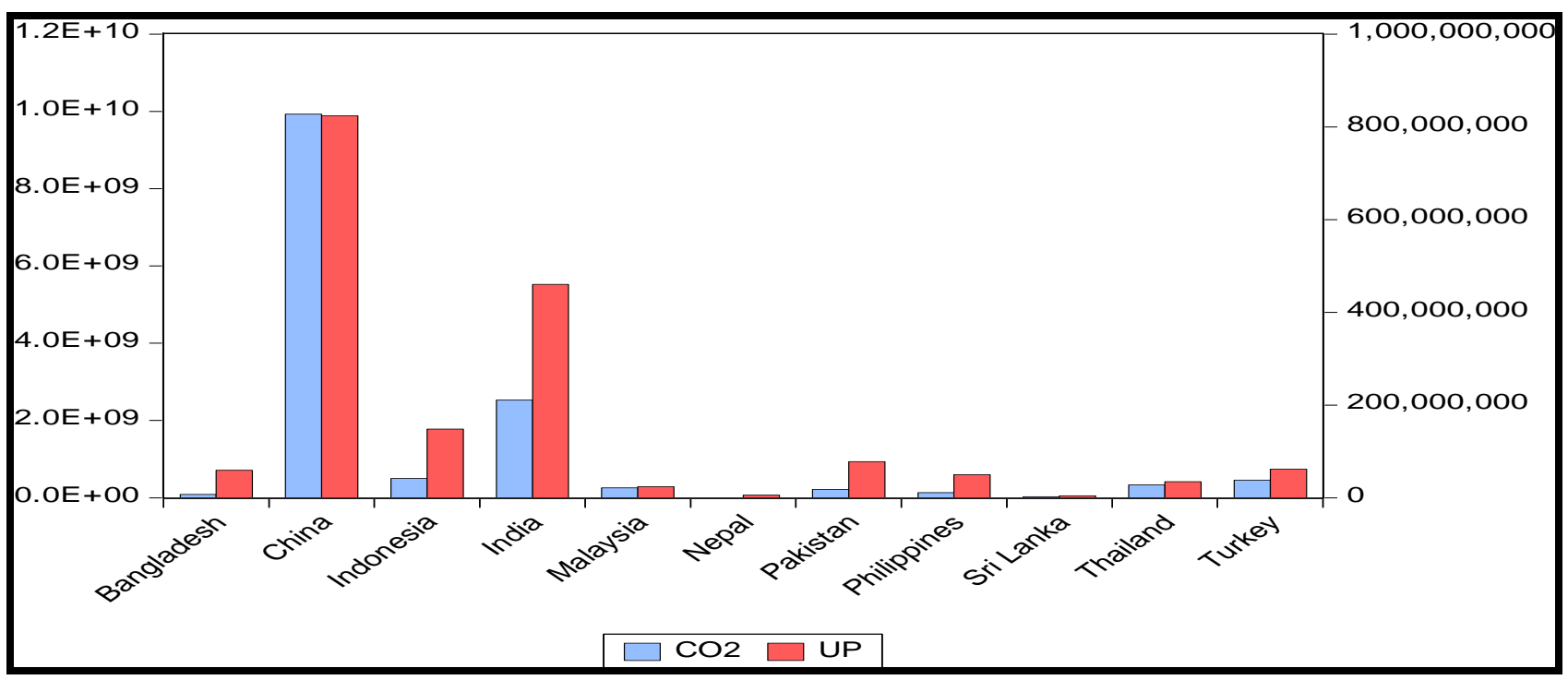

The Urban population trend in emerging but less developed countries in 2018 shows that nonlinear trend. The china has the largest share of Urban population which was 823827650. The second highest Urban population was 460295677 in India. The third one follow ed by Indonesia which was 148084795. Our data sample contains of eleven emerging countries from Asia. All of these economies are from the top twenty FDI hosting economies from last twenty years. These emerging countries encompass their reserve by remittance and foreign direct investment. These countries are more liberal in trade openness and due to trade openness multinational companies transfer their production infrastructure and technologies. The level of trade openness and other globalization process these countries are still in primary stage of development but their pace are very speedy. In 2008 financial crises these economies had speedy adjustment process due to strong financial institution. Due to above mentioned reasons these selected countries are emerging economies in Asia.

The outcomes were estimated with the help of panel data collected from 11 emerging Asian economies from 1990 to 2018. Section 2 provides data and methodology, Section 3 presents estimates and results, 
Section 4 interprets results, Section 5 concludes, and highlights the main policy consequences of the research.

\section{Literature Review}

Assessing the impact of Urbanization, fossil fuels energy consumption, economic growth, FDI, on environmental dilapidation is one of the immensely vital areas of research. In this concern, several efforts have been made by conducting empirical studies by paneling the different income / regional groups and using time series data of different countries. The empirical validation of (EKC) hypothesis is also confirmed in quantity of studies by using panel data and time series of different countries / regions. Some studies which have discussed these features of environmental research are discussed below: Acaravci (2010) explored the relation amongst $\mathrm{CO}_{2}$ emanations, energy ingesting and economic growth in nineteen European economies between 1960 and 2005. The researchers found that the variables were definitely interlinked. In adding, the study demonstrated the analysis of the inverted U-shaped EKC, particularly in Italy and Denmark. The Error Correction Model (ECM) was implemented and this study found that there is a two-directional connection amongst the variables. Attari and Ataria (2011) evaluate the affiliation amongst Energy ingesting and economic growth among 1971 and 2008 through a regional analysis of Pakistan, India and China. Globally, the $\mathrm{CO}_{2}$ emissions rate is $51.35 \%$, but Pakistan has the lowest rate of $85.85 \%$ compared to India and China which was $88.18 \%$ and $87.53 \%$ respectively. Pakistan has high population growth rate, low per capita GDP but low $\mathrm{CO}_{2}$ emissions compared to China and India. Sharma (2011) observed the commitment to $\mathrm{CO}_{2}$ emissions in sixty nine economies by using panel data. To examine those determining $\mathrm{CO}_{2}$ emissions, 69 countries were divided into three subcategories in high, medium and low-income economies. The study originate that urban population has a negative influence on $\mathrm{CO}_{2}$ emanations in middle and low-income countries. Arouri et al. (2012) assessed the association among $\mathrm{CO}_{2}$ emanations, energy ingesting and GDP in Central and North African economies from the period of 1981 to 2005. It determined that the long-term correlation in energy ingesting with $\mathrm{CO}_{2}$ emanations is important and positive and GDP is a quadratic connection with $\mathrm{CO}_{2}$ emanations for the entire world. The data estimate also showed the EKC shaped as inverted U. Remuald (2012) studied the connection between $\mathrm{CO}_{2}$ growths per capita for the period of 1970 to 2004 for 5 countries. The estimation of panel data showd that education is not a factor in $\mathrm{CO}_{2}$ emission growth but education is a factor in pollution growth. GMM-system estimation technique is used in this study. Chen and Huang (2013) analyzed the data of 1981-2009 to find out the connection amongst $\mathrm{CO}_{2}$ emanations, urbanization, FDI, and energy ingesting for the $\mathrm{N}-11$ nations. The results showed a extensive association between carbon emanations and economic growth using panel co-integration. Additionally, urban population has a important and negative relationship with carbon emanations. Sedorsky (2014) explored 16 developing countries and used STIRPAT model from 1971 to 2009.

Practical results suggested a positive correlation among energy intensity, per capita GDP, population size and carbon emanations. While the use of urbanization depends on the method of assessment, may be a positive or negative connection. Cetin and Ecevit (2015) deliberated the relationship among energy ingesting, urbanization, and environmental deprivation in 19 sub-Saharan countries between 1985 and 2010. As a result, it has been revealed that the main source of environmental degradation in these 19 sub- Saharan is energy consumption and urbanization. This study acknowledged the long-term connection amongst the variables applying panel co-integration assessments. The outcomes of the Error Correction Model (VECM) showed that there are two reasons between long-term urbanization and both energy ingesting and $\mathrm{CO}_{2}$ emanations. Alam et al. (2016) detected the consequence of energy ingesting, income and population growth on $\mathrm{CO}_{2}$ discharges by applying annual data from 1970 to 2012 for Indonesia, India, China and Brazil. $\mathrm{CO}_{2}$ emanations has optimistic and significant influence with increase in consumption of energy and income in all four countries. The outcome of populace growth on $\mathrm{CO}_{2}$ emanations was significant for Brazil and India but inconsequential for Indonesia and China. Hypothesis of inverted- EKC was also initiate in China, Indonesia and Brazil but not in India. Smruti and Dash (2017) detected the relationship among FDI, energy intensity, urbanization and $\mathrm{CO}_{2}$ emanations during 1980 to 2012 of 18 republics in South Asia. The researchers divided the 17 countries 
into three sub categories on the basis of income them as middle and low income countries. This investigate divided the nations on the foundation of per capita income. A co-integration association is found between energy intensity, fossil fuel, FDI, urban population and Carbon emanations in middle income nations. The results indicated that energy ingesting significantly increased by the $\mathrm{CO}_{2}$ emissions and incline to create to green house problem in the South Asian Countries. Hanif (2017) inspected the nexus of energy, economics and the environment in Caribbean Latin American countries. The study aimed to discover the influence of fossil fuel ingesting, oil-based imports, electricity consumption, and increase of urban population on environmental collapse. The researcher used the System Generalized Method (SGM) for the period (1990-2015) with two-stage estimator included in a panel of 20 middle and 20 lower middle income nations. The results indicated that the expansion of oil imports, fossil fuel ingesting and urban population is contributing meaningfully to ecological degradation and also established the reveled U-shaped association among $\mathrm{CO}_{2}$ emission and GDP per capita. This study expored that renewable energy resources could support to encounter growing energy demand and reduce trade deficits by reducing oil imports to developing countries in Caribbean Latin American countries. Sakiru and Mulali (2018) investigated the impact of FDI on environmental dilapidation by scrutinize 20 countries.

The results showd that FDI has not any outcome on environmental dilapidation indicators, carbon footprints and ecological footprint. The results further explored that energy ingesting, GDP, and urbanization played key contributors to environmental degradation. The results exposed that FDI and urbanization enhance effluence in the developing countries but they alleviate pollution in developed countries. Hanif, (2018) analyzed "the effect of economic growth on energy ingesting and urban population on $\mathrm{CO}_{2}$ emission in sub-Saharan Africa. The results of study showed the positive and significant influence of economic growth, ingesting of fossil fuels, urban expansion, and renewable energy on environmental dilapidation in evolving nations of sub-Saharan African. In this study (GMM) was adapted on 34 sub-Saharan African economies for the period of 1995-2015. Results described that ingesting of fossil fuels for extension of metropolitan zones and cooking are meaningfully causal to $\mathrm{CO}_{2}$ emission and air pollution. Inverted-U shaped relationship among per capita economic growth and $\mathrm{CO}_{2}$ emission has also found. Empirical analysis also confirmed Environmental Kuznets Curve (EKC) in low- income and middle emerging economies of Sub Saharan Africa. The study suggested that renewable energy replacements improve air value by monitoring $\mathrm{CO}_{2}$ emission and depressing the direct interface of household's noxious gases and use of renewable energy alternative help the economies to attain viable development goals". Shehbaz, et al. (2019) observed the relation amongst FDI and $\mathrm{CO}_{2}$ emanation from 1990-2015 for the Middle East and the North African region. The researcher applied GMM (Generalized Method Moments) for Pollution Haven Hypothesis (PHH) testing. N-shaped connotation found amongst FDI and $\mathrm{CO}_{2}$ emanations. GDP and $\mathrm{CO}_{2}$ emissions has inverted- $\mathrm{U}$ and $\mathrm{N}-$ shaped relationship and thus satisfied the Environmental Kuznets Curve. Hanif, et al. ( 2019) studied FDI, fossil fuels and economic growth that directed to Carbon dioxide emanations in developing countries in asia. Asia's fastest-growing economy is facing increasing environmental problems. Fossil fuels increase the emission of $\mathrm{CO}_{2}$.

FDI in developing economies are important source of $\mathrm{CO}_{2}$ emanations. Results confirmed the Pollution Haven Hypothesis and rejected the Halo effect by hypothesis. Panel data were used from 1990 to 2013 and the ARDL bound approach was applied. This study revealed a optimistic and significant influence of boosting economic growth, fossil fuels and FDI on $\mathrm{CO}_{2}$ emanations and environmental degradation. The study also identified the existence of the EKC. The study concluded that reducing fossil fuel consumption and promoting environmental friendly economic growth strategies in developing countries will be beneficial. Chaudhry et al. (2020) inspected the association amongst economic development, urbanization of $\mathrm{CO}_{2}$ emanations, population size in the economies of the South Asian Association for Regional Cooperation ( SAARC) for the period 1994-2013. In this investigation, an enhanced STIRPAT model along a fixed effect regression estimation is used. Practical results have shown that size of population and high carbon emanations per capita are the main drivers in SAARC economies. There is a 
U-shaped affiliation amongst urban population and $\mathrm{CO}_{2}$ emanations. As urban population increases, $\mathrm{CO}_{2}$ emanations initially decreases and then increases with urbanisation. Prior studies observed the connections between urban development, energy usage and Carbon emissions in developed, developing and low-developed economies. A few preferred studies were mentioned in this report. In addition, a few papers addressed the dissimilar directions in Asian countries for economic degradation.In addition, not one of the prior studies visibly discovered the correlation between urban development, fossil fuels energy usage, GDP, FDI and carbon emissions and the overall effect on $\mathrm{CO}_{2}$ emissions in Asia's emerging economies.

Keeping all these dynamics into review, this study empirically endeavors to discover the association between GDP, urbanization, fossil fuels energy consumption, FDI, and carbon emissions in emerging economies of Asia. Moreover, these economies have been taken into consideration, because these emerging economies of Asia have a few collective features such as growing population, enormous energy consumption, rising urban development and industrialization in the 1990s. By means of this, the existing investigation anticipates to cover the accessible gap in literature. Moreover, this empirical study efforts to inspect, whether rate of urban development, energy usaged, GDP, FDI make easy to $\mathrm{CO}_{2}$ emissions and environmental degradation in emerging economies of Asia.

\section{Methodology and Data Description}

Present study discussed the impact of economic growth, Urbanization, fossil fuel consumption, FDI on environmental dilapidation in the Asian developing economies. Panel data has been taken from the "World Bank Development Indicators 2018". This study has assimilated yearly panel data for the period from 1990 to 2018. Data is collected from 11 emerging Asian economies (Bangladesh, Indonesia, China, India, Turkey, Malaysia, Philippines, Pakistan, Nepal, Thailand, Sri Lanka and time period is taken from 1990 to 2018.

\subsection{Description of the Variables}

\subsubsection{Carbon Emissions $\left(\mathrm{CO}_{2}\right)$}

Log of $\mathrm{CO}_{2}$ emissions per capita per metric ton is used as dependent variable. The supposition is that economic progress donates to carbon emanations/emissions and also scrutinize Environmental Kuzzet Curve (EKC) relationship. According to the theory, economic growth donates to $\mathrm{CO}_{2}$ emissions/emanations and these $\mathrm{CO}_{2}$ emissions/emanations follow reversed U-shaped (EKC) relationships. In preceding studies Shahbaz et al. (2013); Hanif (2018); Sabori (2013) had been used these variables in their studies.

\subsubsection{Economic Growth (GDP)}

Economic growth is enumerated by taking the log of yearly per capital GDP rate. Shahbaz et al. (2013), Hanif (2017) and Ahmed and Doe (2017) have also used economic growth as Regressor or independent variable. One of the supposition of this study is that real GDP per capita growth contributes to $\mathrm{CO}_{2}$ secretions.

\subsubsection{Economic Growth Squared (GDP2)}

Log of Square of the real GDP is used to measure the EKC hypothesis. Shahbaz et al. (2013); Ahmed and Long (2012); EKC has also constructed a square of GDP in their model to check the hypothesis. The evidence of the study is that the suqared of GDP per capita is negatively correlated with carbon emissions.

\subsubsection{Fossil fuels usage (FFU)}

Fossil fuels usage are recorded as annual energy consumption. Hanif (2019); Ahmad and Du (2017); and Lau et al. ( 2014) used fossil fuel to inspect the properties of usage of energy on $\mathrm{CO}_{2}$ emanations. The use of fossil fuel energy is speculated to upsurge carbon emissions/emanations.

\subsubsection{Foreign Direct Investment (FDI)}


Foreign direct investment net income (BoP, current US dollars) is being used to assess its impact on $\mathrm{CO}_{2}$ emissions. Then it is converted into real terms by dividing with GDP deflator according to the previous research by Lau et al. (2014); Cole (2004); and Zarsky, (1999). In previous studies, there are both positive and negative effects of FDI on $\mathrm{CO}_{2}$ emissions. In some studies FDI indicates a lessening in $\mathrm{CO}_{2}$ emanations and proves the halo effect hypothesis.

\subsubsection{Urbanization (URP)}

In this study researcher has used log of urban population as percentge of total population to measaure the impression on carbon emissions. This is also used in the prior studies of Ahmed and Du (2017) and Hanif and Santos (2017). It is estimated that increasing population escalate carbon emanations.

\subsection{Model Specification}

To scrutinize the effect of fossil fuel consumption, economic growth, FDI and urbanization on $\mathrm{CO}_{2}$ emanations/environmental degradation. The current study exercises the EKC hypothesis which is based on Kuznets'(1995) hypothesis. Kuznets initially found inverted U-shaped relation among $\mathrm{CO}_{2}$ emanations and economic growth. While the same impression is used to validate the association between economic growth and the environment, the expression "environmental Kuznets curve" was designed. By "EKC" hypothesis, Economic growth firstly increases $\mathrm{CO}_{2}$ emanations, but in future, instead of gaining a sure turning point, it increases economic growth and reduces $\mathrm{CO}_{2}$ emanations.

The econometric form of the model is based on prior studies by Hanif and Santos (2017 a) and Shahbaz et al. ( 2012) can be described as follows:

$$
C \mathrm{O}_{2}=f\left(G D P, G D P^{2}, \varnothing\right)
$$

Equation (1) $\varnothing$ expressions an unknown factor (such as FDI, urban population and fossil fuel energy consumption ) and their probable impact on carbon emissions and equation becomes:

$$
\mathrm{CO}_{2}=f\left(G D P, G D P^{2}, U R P, F F U, F D I\right)
$$

$\mathrm{CO}_{2}=\mathrm{CO}_{2}$ emanations/emissions per capita

GDP $=$ Gross Domestic Product Per capita

GDP2 $=$ Squared of Gross Domestic Production

URP $=$ Urban population to the percentage of total population in millions

$\mathrm{FFU}=$ Annual consumption of fossil fuels ( $\mathrm{kg}$ of oil equivalent per capita)

FDI = Foreign Direct Investment (BoP, current US\$)/ GDP deflator/total population

The econometric model to assess the results can be transcribed as:

$$
C O_{2 i t}=\beta_{0}+\beta_{1} G D P_{i t}+\beta_{2} G D P_{i t}^{2}+\beta_{n} \emptyset_{i t}+U_{i t}
$$

To estimate the results and the extended form of the EKC hypothesis can be printed as:

$$
\begin{gathered}
\ln C O_{2 i t}=\beta_{0}+\beta_{1} \ln G D P i t+\beta_{2} \ln G D P 2 i t+\beta_{3} \ln F F U_{i t}+\beta_{4} \ln F D I_{i t}+\beta_{5} \ln U R P i t \\
+\varepsilon i t \ldots \ldots \ldots \ldots \ldots \text { (4) }
\end{gathered}
$$

Here $t$ represents time when $i$ represent the country. The lower case letters symbolize variable logarithmic changes. In addition, the individual error term is used in Equation (4) eit and it implies that errors are distributed identically (i.i.d.). The individual errors or time fluctuating errors.

In Equation (4), logit model is used as it is assumed that GDP Per capita and CO2 excretions will not have a relationship that is linear but may have a relationship that is exponential. In addition, to lessen the issue of multicollinearity the researcher used log traformation. Natural logs are used to examine the effects of independent variables on environmental degradation (carbon emissions). Equation ( 4) presents a long-term association between regressing and regressing variables. In order to use the PMG/ARDL model, it is necessary to add short-term dynamics to the long-term equation (4); this is given as an equation ( 5). 


$$
\begin{aligned}
& \triangle \operatorname{lnCO} \mathrm{O}_{2 i t}=\theta_{0}+\sum_{j=1}^{k} \theta_{1 j} \triangle \operatorname{lnCO} 2 t-j+\sum_{j=0}^{k} \theta_{2 j} \triangle \operatorname{lnGDP_{t-j}}+\sum_{j=0}^{k} \theta_{3 j} \triangle \operatorname{lnGDP^{2}t-j}+\sum_{j=0}^{k} \theta_{4 j} \triangle \ln F F U_{t-j}+\sum_{j=0}^{k} \theta_{5 j} \triangle \ln F D I_{t-j} \\
& +\sum_{\theta_{6 j}}^{k} \triangle \ln U R P_{t-j}+\beta_{1} \ln C O_{2 i t-1}+\beta_{2} \ln G D P_{i t-1}+\beta_{3} \ln G D P^{2}{ }_{i t-1}+\beta_{4} \ln F F U_{i t-1}+\beta_{5} \ln F D I_{i t-1} \\
& +\dot{j}_{6}{ }_{6} \text { lnURP } P_{i t-1}+\varepsilon i t
\end{aligned}
$$

In eqution (5), $\triangle$ shows the first difference operator, $\beta$ s embodies the long run coefficient, $\theta$ s present the short term coefficient, and eit shows for the commonly distributed error with mean zero. Moreover, in order to prevent long-term co-integration, there is null hypothesis of no co-integrtion mong the variables. The alternative hypothesis on the other hand is that there exist a contegration amongst the variables.

Pedroni test is used to examine the the null hypothesis, F-statistics of test are observed to inspect the association of dependence and the mutual alliance between the independent variables and the analyzed F- Compare statistical comparisons with key values formed by Pesaran et al. (2001). Once the long-term association is documented, then a random error correction procedure is devised here, which adds speed to the adjustment or model to add speed to the short-term to long-term transition.

$$
\begin{aligned}
\Delta \ln C O_{2 i t}=\beta_{0}+ & \sum_{i=1}^{n} \alpha_{i 1} \Delta \ln C O_{t-i}+\sum_{i=1}^{n} \gamma_{2 i} \Delta \ln G D P_{i t-1}+\sum_{i=1}^{n} \sigma_{3} \Delta \ln G D P_{i t-1}^{2}+\sum_{i=1}^{n} \theta_{4} \Delta \ln F F U_{i t-1}+\sum_{i=1}^{n} \tau_{5} \Delta \ln F D I_{i t-1} \\
& +\sum_{i=1}^{n} \omega_{6} \Delta \ln U R P_{i t-1}+\beta_{1} \ln G D P_{i t}+\beta_{2} \ln G D P_{i t}^{2}+\beta_{3} \ln F F U_{i t}+\beta_{4} \ln F D I_{i t}+\beta_{5} \ln P+\delta E C_{i t-1}+U_{i t}
\end{aligned}
$$

Here, $\delta$ regulate the coefficient of the ECT and to confirm the co-integration association. The value of ECT is predicted negative sign and also statistically significant.

\begin{tabular}{ccccc}
\multicolumn{5}{c}{ Variables and data source description } \\
\hline Variables & Proxies & Descriptions & Sources of data & Ranges of dat \\
\hline Environmental degradatic & CO2 & Carbon Dioxide & WDI \&World development Atlas & $1990-2018$ \\
Economic Growth & GDP & Gross Domestic Product & World development indicator & $1990-2018$ \\
Investment & FDI & Foriegn Direct Investmer & World development indicator & $1990-2018$ \\
$\begin{array}{c}\text { Energy consumption } \\
\text { Technology }\end{array}$ & FFU & Fossils Fuels & WDI \&Global Energy Statistical bor & $1990-2018$ \\
\hline U11 & Urbanization & World development indicator & $1990-2018$ \\
\hline
\end{tabular}

All variables data are taken from world development indicators, world development atlas and Global Energy statistical book year 2019. All variables are used in log form.

\begin{tabular}{|c|c|c|c|c|c|}
\hline \multicolumn{6}{|c|}{$\begin{array}{c}\text { Table } 1 \\
\text { Summary Statistics }\end{array}$} \\
\hline & $\mathrm{CO}_{2}$ & FFU & FDI & GDP & URP \\
\hline Mean & 2.04 & 63.83 & 0.70 & 3031.70 & 38.05 \\
\hline Median & 1.00 & 63.55 & 0.25 & 1821.18 & 33.84 \\
\hline Maximum & 7.94 & 96.94 & 6.29 & 13853.10 & 73.61 \\
\hline Minimum & 0.03 & 5.05 & -0.64 & 354.257 & 8.85 \\
\hline Std. Dev. & 1.99 & 22.22 & 1.12 & 2966.64 & 16.44 \\
\hline
\end{tabular}

\section{Analysis of Results}

\subsection{Summary Statistics}

The researcher reported the Summary statistics of all the variables in table 1. Fossil fuels energy consumption (FFU), FDI and urban population (URP) are weakly associated with the $\mathrm{CO}_{2}$ emissions .

Note: author's own calculation

\subsection{Testing of Multicollinearity}

In this estimation correlation method is applied to check the issue of multicollinearity . The outcomes of the correlation coefficients demonstrate the correlation amongst the variables. The outcomes indicate that fossil fuels energy usage (FFU), FDI, GDP per capita (GDP) and urban population (URP) are inadequately connected with the dependent variable " $\mathrm{CO}_{2}$ emissions" . 
Table 2: Correlation Matrix

\begin{tabular}{|c|c|c|c|c|c|}
\hline & $\mathrm{LCO}_{2}$ & LFFU & LFDI & LGDP & LURP \\
\hline $\mathrm{LCO}_{2}$ & 1.00 & & & & \\
\hline LFFU & 0.81 & 1.00 & & & \\
\hline LFDI & 0.81 & 0.63 & 1.00 & & \\
\hline LGDP & 0.86 & 0.61 & 0.78 & 1.00 & \\
\hline LURP & 0.83 & 0.77 & 0.62 & 0.78 & 1.00 \\
\hline
\end{tabular}

Noted: author's own calculation.

The values of (VIF) is shown in Table 3 below. The value of the VIF fluctuates from 1.592 to 3.840 , which means that there is no matter of multicollinearity in the evaluated model.

Table 3: Variance Inflation Factor(VIF)

\begin{tabular}{cccccc}
\hline & LCO $_{2}$ & LFFU & LFDI & LGDP & LURP \\
\hline LCO 2 & - & & & & \\
LFFU & 2.915 & - & & & \\
LFDI & 1.468 & 1.201 & - & - & \\
LGDP & 1.102 & 1.064 & 1.093 & 1.124 & - \\
LURP & 1.024 & 1.091 & 1.717 & & \\
\hline
\end{tabular}

\subsection{Testing for Stationarity}

To evaluate the reliability of the results and to avoid the spurious results, the researcher applied the unit root tests for stationary status of the variables in the panel data series, because non-stationary variables produce ambiguous results. The results are elaborate in Table 4

Table 4: Summary of Panel Unit Root

\begin{tabular}{|c|c|c|c|c|c|c|c|c|c|}
\hline \multicolumn{5}{|c|}{ Levin-Lin-Chu test } & \multicolumn{5}{|c|}{ IPS-W test } \\
\hline \multirow{2}{*}{ Variables } & \multicolumn{2}{|c|}{ At Level } & \multicolumn{2}{|c|}{ At Difference } & \multicolumn{2}{|c|}{ At Level } & \multicolumn{2}{|c|}{ At Difference } & \multirow[b]{2}{*}{ Order } \\
\hline & Stats & P-value & Stats & P-value & Stats & P-value & Stats & P-value & \\
\hline $\mathrm{LCO}_{2}$ & -1.54 & 0.064 & -5.09 & 0.0000 & 1.41 & 0.9200 & -7.20 & 0.0000 & $\mathrm{I}(1)$ \\
\hline LFFU & -0.59 & 0.0000 & -3.46 & 0.0000 & -3.59 & 0.0000 & -4.74 & 0.0000 & $\mathrm{I}(0)$ \\
\hline LFDI & -5.80 & 0.0000 & -9.45 & 0.0000 & -5.95 & 0.0000 & -11.02 & 0.0000 & $\mathrm{I}(0)$ \\
\hline LGDP & 1.72 & 0.957 & -4.00 & 0.0000 & 7.57 & 0.9999 & -5.15 & 0.0000 & $\mathrm{I}(1)$ \\
\hline LGDP $^{2}$ & 2.41 & 0.992 & -3.37 & 0.0000 & 8.45 & 0.9999 & -4.65 & 0.0000 & $\mathrm{I}(1)$ \\
\hline LURP & -4.14 & 0.0000 & 0.97 & 0.8350 & -2.42 & 0.0070 & 1.85 & 0.9680 & $\mathrm{I}(0)$ \\
\hline
\end{tabular}

Note: author's own calculation

In table 4 the outcomes show that the $\mathrm{CO}_{2}$ emission, GDP and GDP 2 are stationary at first difference and co-integration order is I(I), while fossil fuels consumption FFU, FDI and URP variables are stationary at level and co-integration order is I(0). Therefore, it can be recognized that the variables have mixed order of integration; thus, for co-integration testing Pedroni co-integration test is used. Co-integration method is appropriate for large data set. In small sample data set, result may display excessive unpredictability. In distinction, the ARDL bound test righteous belongings for small sample data (Saboori \& Sulaiman, 2013; Zhang \& Gao, 2016). PMG/ARDL model is used to estimate the impact of FDI, GDP, URP and FFU on $\mathrm{CO}_{2}$ emissions in the selected emerging Asian economies.

\subsection{Testing of Panel Dependence}

A lot of tests are provided in the prior work to learn about cross-sectional dependence on panel results, and the most widely used tests are Baltgi Feng, pacers (2004 A, B), Scaled LM (2004), Breusch and Pagan (1980) and Kao Bias based scaled LM (2012) are incorporated in different studies. The aforementioned assessment outcomes are listed in Table 5. Complete findings are reported in the table below did not support cross-sectional dependency, suggesting that the first generation panel root test is more suitable for implementation. 
Table 5

\begin{tabular}{ccc}
\hline Test & Statistics & P. value \\
\hline Breusch Pagan LM & 41.76 & 0.9050 \\
Pesaran CD test & 1.63 & 0.1020 \\
\hline
\end{tabular}

\subsection{Testing for Heteroscedasticity}

To test heteroscedasticity of the model, we used Bresush- Pagan test. The outcomes are following.

Table 6: Results for Heteroscedasticity

\begin{tabular}{ccc}
\hline \multirow{2}{*}{ Joint-chi $^{2}$ test } & F-statistics & P-Value \\
\cline { 2 - 3 } & 0.6488 & -0.429 \\
\hline
\end{tabular}

\subsection{Testing for Serial Correlation}

The serial correlation is verified using Langrangian Multiplier Test. Here it is considered null hypothesis that there is no serial correlation in model. The results are reported in table 7. The result shows acceptance of the serial correlation in the model by null assumption.

Table 7: Results for Serial Correlation

\begin{tabular}{|c|c|c|}
\hline \multirow{2}{*}{ Prob. > chi ${ }^{2}$ test } & F-statistics & P-Value \\
\hline & 1.22 & 0.292 \\
\hline
\end{tabular}

\subsection{Functional Form}

The functional form specification is verified using Joint-Jarque Bera test. The null hypothesis is considered that there is no misspecification in functional form of the model. The results are reported in table 8 . The result shows acceptance of the serial correlation in the model by null assumption.

Table 8: Results for Functional Form

\begin{tabular}{ccc} 
Prob. $>$ chi $^{2}$ test & F-statistics & P-Value \\
\cline { 2 - 3 } & 0.52 & 0.824
\end{tabular}

\subsection{Pedroni Co-Integration Testing}

The Pedroni-test is being used to underpin the co-integration of GDP, GDP ${ }^{2}$ fossil fuels energy usage (FFU), urbanization (URP), FDI and $\mathrm{CO} 2$ emissions. The results of this test are described in Table 9. Here, the outcomes of the test validates a co-integration association of dependent and independent variables. Moreover, Kao test also validate the co-integration relationship. The null hypothesis is considered that there is no co-integration exist in the model.

Table 9: Results of Pedroni Co-integration Test

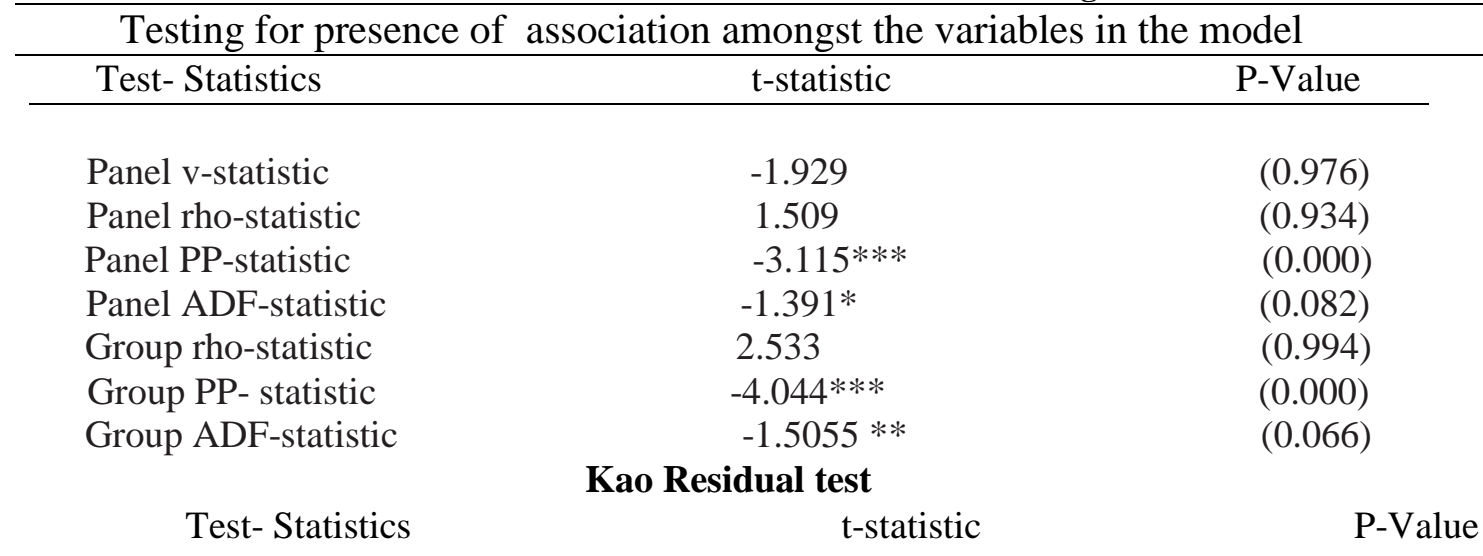


Note: $* * *$ and $* * *$ represents $10 \%, 5 \%$ and $1 \%$ level of significance respectively

\section{Discussion}

\subsection{Co-integration Analysis in the Long-Run}

PMG/ARDL model is used to study long-term connection among dependent Variable $\mathrm{CO}_{2}$ emissions and independent variables GDP, square of GDP, fossil fuels energy usage, urbanization URP and FDI. The results of the PMG/ARDL estimates are listed in Table 10.

Table 10: Estimation of Panel PMG/ARDL Approach

Dependent Variable $=\log \mathrm{CO}_{2}$ Number of Observations: 245/Number of Panels:11

\begin{tabular}{ccccc}
\hline Regressors & Coefficient & Standard Error & t-Statistic & P-values \\
LFFU & $0.940^{* * *}$ & 0.145 & 6.456 & 0.000 \\
LFDI & $0.036^{* * *}$ & 0.006 & 5.536 & 0.000 \\
LGDP & $4.412^{* * *}$ & 0.948 & 4.650 & 0.000 \\
LGDP2 & $-0.697^{* * *}$ & 0.161 & -4.323 & 0.000 \\
LURP & $1.315^{* * *}$ & 0.231 & 5.682 & 0.000 \\
\hline
\end{tabular}

Note: $* * *, * *$ and $*$ represents the significance level at 1\%, 5\% and 10\%, respectively

Results in the long-run of PMG model show that GDP significantly increases $\mathrm{CO}_{2}$ emissions/emanations. As increase in GDP give rise $\mathrm{CO}_{2}$ emissions also. More specifically, in the long run, every one per cent increase in GDP increases $\mathrm{CO}_{2}$ emissions by around 4.412 per cent. These result shows that GDP in emerging Asian countries arises at the expense of increasing $\mathrm{CO}_{2}$ emanations. These results are consistent with Ziaei (2015); Kais and Sami (2016); Hanif (2017).

The present study also shows that square of GDP is negatively correlated with $\mathrm{CO}_{2}$ emissions, showing that every one percent increase in squred GDP decreases $\mathrm{CO}_{2}$ emissions by around 0.697 percent. These experimental results confirm the inverted U-shaped association between squred GDP and $\mathrm{CO}_{2}$ emissions in developing Asian countries. The results confirmed the presence of EKC and showed that increasing GDP increase $\mathrm{CO}_{2}$ emissions, and that further increases in GDP after a certain level reduce $\mathrm{CO}_{2}$ emissions (Esso and Keho, 2016; Hanif, 2018).

It results also shows that the use of fossil fuel energy in developing Asian economies also boost $\mathrm{CO}_{2}$ emissions, and stated as every one percent rise in use fossil fuels energy will increase the $\mathrm{CO}_{2}$ emissions by 0.940 percent, if all other factors held constant. So, use of fossil fuels energy is indeed rising $\mathrm{CO}_{2}$ emissions and is playing a important role in environmental degradation in emerging Asian countries, and this has led to the adoption of the Sadorsky (2014) and Heidari et al. (2015). In developing countries, use of fossil fuels energy is used to accelerate GDP and meet growing energy needs.

As such, energy use is certainly increasing $\mathrm{CO}_{2}$ emissions and is playing a substantial role in environmental degradation in emerging Asian countries, approving the results of the Shrestha et al. (2009); Wolde-Rufael and Menyah (2010); Sadorsky (2014); Heidari et al. (2015). These practical results are not inconsistent, because in developing Asian countries, use of fossil fuels energy is used to accelerate GDP. Like many other developing regions, Asian rising economies are plaster economic competitors and are constantly struggling to restore the living standards of their inhabitants. Moreover, the use of fossil fuels energy increases $\mathrm{CO}_{2}$ emissions is higher in emerging Asian countries due to less efficient oil-based techniques: these economies use less of fossil fuels energy while producing less, reduce their environmental degradation and improve health issues in the region.

FDI has a significant and positive impact on $\mathrm{CO} 2$ emissions in selected Asian countries in the estimation of present study. It has shown that if all other factors remain constant, an increase of one per cent in FDI will increase CO2 emissions by an average of 0.036 per cent. It has shown that FDI is a key 
source of high $\mathrm{CO} 2$ emissions in selected Asian countries.

Although we believe that FDI play a significant impact on income and job creation in Asian countries, this assistance can be compensated for in terms of the negative externalities of foreigners and the fitness of their residents. This result therefore identifies the need for emerging Asian countries to adopt the undesirable environmental characteristics of FDI. Otherwise, environmental degradation could set the stage for the end of the economic depression and could make previous growth unsustainable (Henderson and Millimet, 2007; He, 2006).

These consequences present a positive and statistically significant relation between the urban populace and $\mathrm{CO}_{2}$ emanations in developing countries in Asia. Exactly, every one percent increase in the urban population increases $\mathrm{CO}_{2}$ emissions by 1.315 percent, if all other factors remain constant. Since when the urban population grows, it increases industrialization, which in turn increases the $\mathrm{CO}_{2}$ emissions and economic downturn of Asian economies. This result is in line with the results of Rafiq et al. (2016), Hanif and Gago-de-Santos (2017).

\subsection{Co-integration Analysis in Short-run Relationship:}

PMG/ARDL model is employed to study the association of energy used, GDP and FDI with $\mathrm{CO}_{2}$ emanations in the short-run. The results are in table 11.

Table:11 Estimates of Panel PMG/ARDL Approach in the Short Run

\begin{tabular}{|c|c|c|c|c|}
\hline Regressors & Coefficient & Standard Error & t-Statistic & P-values \\
\hline $\operatorname{dlog} \mathrm{CO}_{2}(-1)$ & $0.977 * * *$ & 0.011 & 85.924 & 0.000 \\
\hline dlog FFU & $0.712 * * *$ & 0.142 & 5.013 & 0.000 \\
\hline dlog FFU(-1) & -0.715 & 0.135 & -5.274 & 0.220 \\
\hline dlog FDI & -0.007 & 0.006 & -1.216 & 0.225 \\
\hline dlog FDI(-1) & 0.006 & 0.005 & 1.140 & 0.225 \\
\hline dlog GDP & -0.084 & 1.208 & -0.070 & 0.944 \\
\hline dlog GDP(-1) & 0.128 & 1.213 & 0.106 & 0.914 \\
\hline dlog GDP 2 & 0.115 & 0.169 & 0.680 & 0.496 \\
\hline dlog $\operatorname{GDP}^{2}(-1)$ & -0.119 & 0.171 & -0.697 & 0.486 \\
\hline dlog URP & $0.749 *$ & 0.428 & 1.751 & 0.081 \\
\hline dlog URP(-1) & $-0.748^{*}$ & 0.426 & -1.755 & 0.080 \\
\hline $\mathrm{C}$ & -0.103 & 0.186 & -0.556 & 0.578 \\
\hline
\end{tabular}

Note: $* * *, * *$ and $*$ represents the significance level at $1 \%, 5 \%$ and $10 \%$, respectively.

In table 11, 0.977 percent of $\mathrm{CO}_{2}$ emanations in a specific time period is accompanying with a $1 \%$ increase in $\mathrm{CO}_{2}$ emissions in the past. Furthermore, in the short term, use of fossil fuels (FFU) energy and urbanization (URP) has a statistically significant impact on $\mathrm{CO}_{2}$ emissions. results show that if every one percent increase in FFU helps to emit 0.712 percent of $\mathrm{CO}_{2}$ in the short term, if all other factors remain constant. One percent increase in urbanization will increase the $\mathrm{CO}^{2}$ emissions 0.749 percent. More over, GDP and FDI do not play a significant role in lowering $\mathrm{CO}_{2}$ emissions in the short run.

Table: 12

Panel Error Correction Model

\begin{tabular}{|c|c|c|c|}
\hline Regressors & Coefficient & Standard Error & t-Statistic \\
\hline$\triangle \log \mathrm{FFU}$ & 0.920885 & 0.521635 & 1.765384 \\
\hline$\triangle \log$ FDI & -0.004874 & 0.006874 & -0.709031 \\
\hline$\triangle \mathrm{dlog}$ GDP & 8.164744 & 14.22678 & 0.57390 \\
\hline$\triangle \mathrm{d} \log \mathrm{GDP} 2$ & -1.346438 & 2.272279 & -0.59255 \\
\hline$\triangle \mathrm{d} \log \mathrm{URP}$ & 12.21799 & 8.780549 & 1.391484 \\
\hline
\end{tabular}


Finally, the outcomes of the error correction demonstrate that the term error correction (ECt-1) is statistically significant and negative. The consequence of the lagged error correction term authorizes the long-term association of fossil fuels energy used, economic growth, urbanization and FDI with carbon emissions. In addition, the negative sign of the term error correction indicates the estimated balance of the model, and $30.3 \%$ of the error will be corrected from the short to the long term each year. The coefficient value of ECM (-1) is 0.303 which is negative and significant. It means if there is any shock in the data of the model, the model has the power to restore the equilibrium level in approximately 3.30 year.

The formula of speed of adjustment is given below:

$$
\begin{gathered}
\text { speed of adjustment }=\frac{1}{\text { the coefficient of ECM }} \\
\text { speed of adjustment }=\frac{1}{0.303} \\
\text { speed of adjustment }=3.30 \text { year }
\end{gathered}
$$

\subsection{Turning point of EKC}

This study also prove the inverted-U shaped Environmental Kuzett Curve (EKC). In this study the researcher also calculate the turning point of EKC which is in the data range.

$$
\begin{gathered}
=\text { Antilog of }\left(-\left(0.5 \times \frac{\text { coefficient Attach with GDP }}{\text { Coefficient attached with the quadratic term of GDP }}\right)\right) \\
=\text { Antilog of }-\left(0.5 \times \frac{4.412}{-0.697}\right) \\
=\text { Antilog }(3.165) \\
\text { Turning Point }=1462.177
\end{gathered}
$$

\subsection{Stability Test}

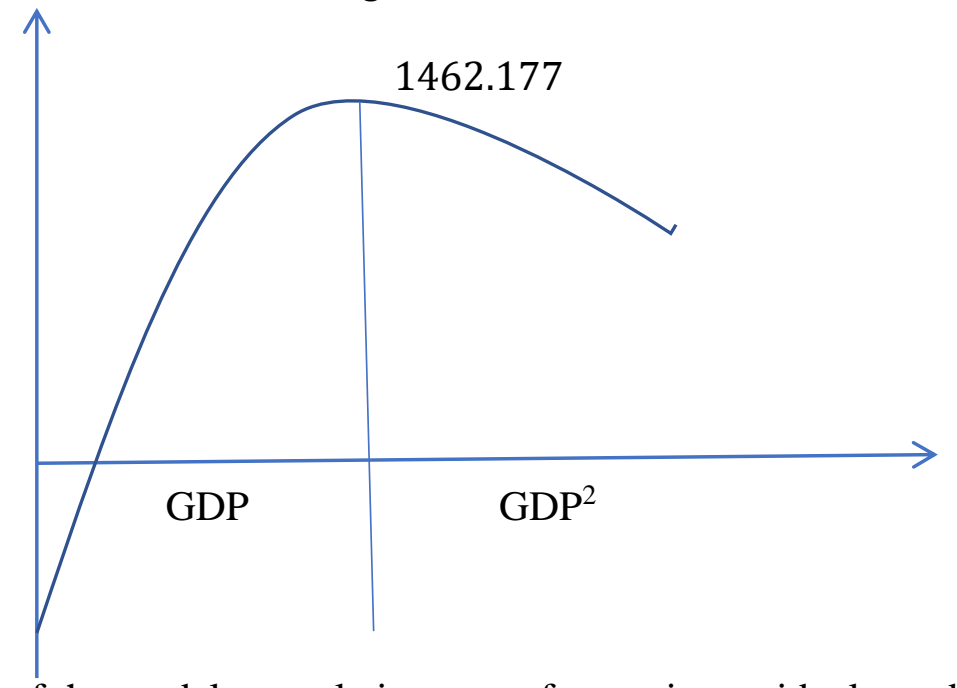

To check the steadiness of the model, cumulative sum of recursive residuals and square cumulative sum of the recursive residual have calculated.

The CUSUM and square CUSUM are represented graphically in the upper and lower key boundaries of the 5 percent of level of significance. Therefore, both the graphs support the stability of the calculated model.

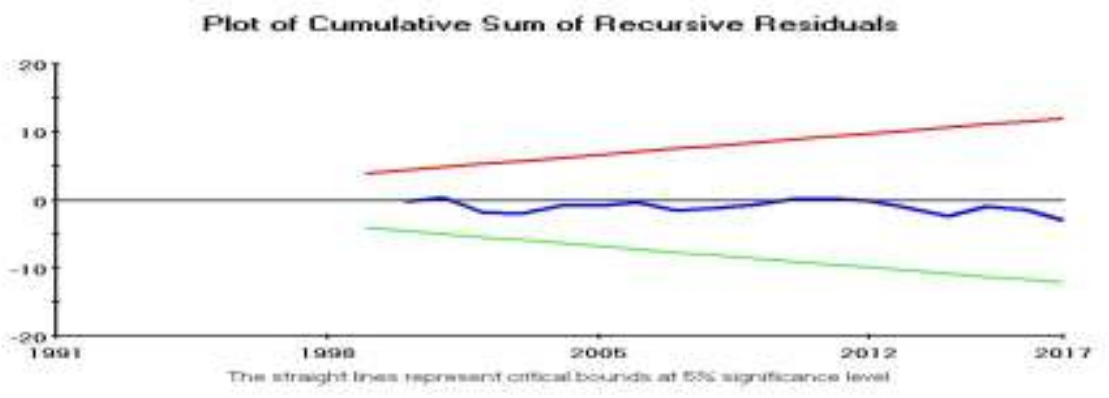


Plot of Cumulative Sum of Squares of Recursive Residuals

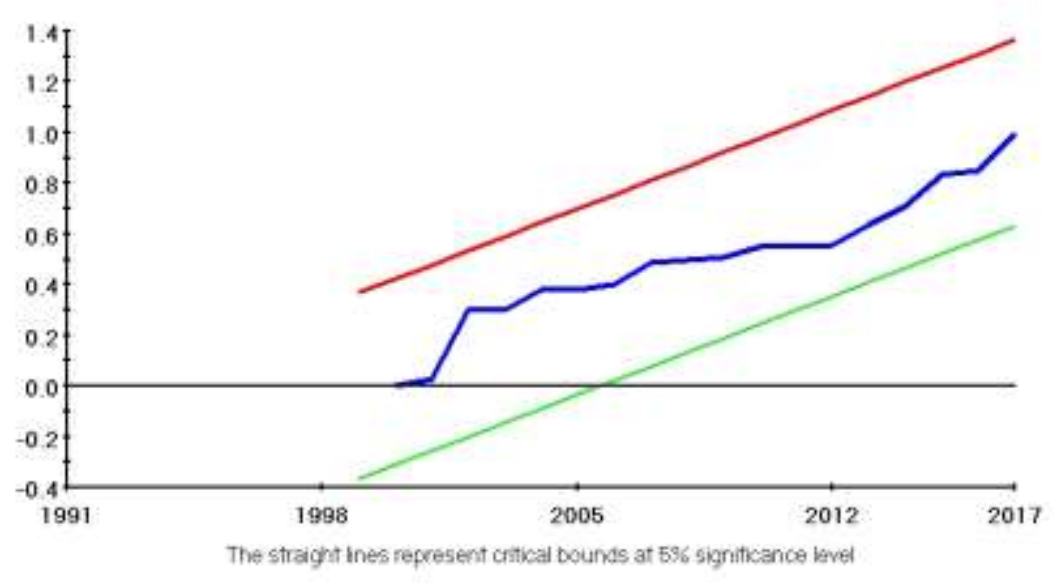

\section{Conclusion}

This research has reinforced the suggestions that economic growth, fossil fuels energy ingestion, urbanization and (FDI) foreign direct investment validate the production of carbon emissions in rising economies of Asia. However the influence of population growth (urbanization) on carbon productions is also create an optimistic impact, this has not verified significant results in the short-run. The technique of the analysis has emphasized the long-run and short-run impacts. The main findings of the study are:

Increase in GDP give rise $\mathrm{CO}_{2}$ emissions also. These results are consistent with Ziaei (2015); Kais and Sami (2016); Hanif (2017). The results also shows that square of GDP is negatively correlated with $\mathrm{CO}_{2}$ emissions. The results confirmed the presence of EKC and showed that increasing GDP increase $\mathrm{CO}_{2}$ emissions, and that further increases in GDP after a certain level reduce $\mathrm{CO}_{2}$ emissions (Esso and Keho, 2016; Hanif, 2018). It results also shows that the use of fossil fuel energy in developing Asian economies also boost $\mathrm{CO}_{2}$ emissions, use of fossil fuels energy is indeed rising $\mathrm{CO}_{2}$ emissions and is playing a important role in environmental degradation in emerging Asian countries, and this has led to the adoption of the Sadorsky (2014) and Heidari et al. (2015). In developing countries, use of fossil fuels energy is used to accelerate GDP and meet growing energy needs. Approving the results of the Shrestha et al. (2009); Wolde-Rufael and Menyah (2010); Sadorsky (2014); Heidari et al. (2015). FDI has a significant and positive impact on $\mathrm{CO} 2$ emissions in selected Asian countries in the estimation of present study. This result therefore identifies the need for emerging Asian countries to adopt the undesirable environmental characteristics of FDI. Otherwise, environmental degradation could set the stage for the end of the economic depression and could make previous growth unsustainable (Henderson and Millimet, 2007; He, 2006). When the urban population grows, it increases industrialization, which in turn increases the $\mathrm{CO}_{2}$ emissions and economic downturn of Asian economies. This result is in line with the results of Rafiq et al. (2016), Hanif and Gago-de-Santos (2017).

\section{Limitations}

The latest data of other environmental gases and impact of other source of Energy can be estimated. These results are estimated with just PMG/ARDL techniques. This study considers just eleven emerging Economies.

\section{Suggestion}

Future research can be extended by applying latest year data of carbon emission and other greenhouse gases and energy sources can be disaggregated and impact on human beings. The estimation can be made by using latest econometrics techniques such as DOLS or FMOLS. The results can be made on region wise and different Economies. 


\section{Reference}

Acaravci, A. \& Ozturk, I.(2013). On the relationship between energy consumption, $\mathrm{CO}_{2}$ emissions and economic growth in Europe. Energy , 35(12):5412-20.

Ahmad, K., \& Long, W. (2012). Environmental Kuznets curve and Pakistan: an empirical analysis. Proc Econ Finanan, 1-14.

Ahmad N, Du L. Effects of energy production and CO2 emissions on economic growth in Iran: ARDL approach. Energy 2017;123:521e37.

Alam, A., Azam, M., Abdullah, A. B., Malik, I. A., Khan, A., Hamzah, T. A. A. T., Zaman. (2016). Environmental quality indicators and financial development in Malaysia: unity in diversity. Environmental Science and Pollution Research, 22(11), 83928404. doi:10.1007/s11356-014-15

Al-Mulali, U., \& Ozturk, I.(2015). The effect of energy consumption, urbanization, trade openness, industrial output, and the political stability on the environmental degradation in the MENA (Middle East and North African) region. Energy 84:382-389.

Al-Mulali, U., Wai, C.W., Ting, L.S., \& Mohammed, A.H. (2015). Investigating theenvironmental Kuznets curve (EKC) hypothesis by utilizing the ecological footprint as an indicator of environmental degradation. Ecol Indicat, 48.

Arouri, M. E. H., Youssef, A. B., M'henni, H., \& Rault, C. (2012). Energy consumption, economic growth and $\mathrm{CO} 2$ emissions in Middle East and North African countries. Energy Policy, 45, $342 \mathrm{e} 349$.

Baltagi, B. H., Feng, Q., \& Kao, C. (2012). A Lagrange Multiplier test for cross-sectional dependence in a fixed effects panel data model. Journal of Econometrics, 170(1), 164-177.

Breusch TS, Pagan AR (1980) The Lagrange multiplier test and its applications to model specification in econometrics. Rev Econ Stud 47(1):239-253

Cetin, M. \& Ecevit, E. (2015). Urbanization energy consumption and CO2 emission in Sub-Saharan countries: a panel co-integration and causality analysis. J Econ Dev Stud 3(2), 66-76

Chaudhry, I. S., Baloch, Z. A., Tan, Q., Iqbal, N., Mohsin, M., Abbas, Q. \&Iqbal, W. (2020). Trilemma assessment of energy intensity, efficiency, and environmental index: evidence from BRICS countries. Environmental Science and Pollution Research. doi:10.1007/s11356-020-09578-3

Chen, J-H. \& Huang, Y-F. (2013). The study of the relationship between carbon dioxide and economic growth. J Int Glob Econ Stud, 6(2),45-61.

Cole, M.A. (2004). Trade, the pollution haven hypothesis and the environmental Kuznets curve: examining the linkages. Ecol Econ , 48(1),71-81.

Esso LJ, Keho Y. Energy consumption, economic growth and carbon emissions: Co-integration and causality evidence from selected African countries. Energy 2016;114:492e7.

Guttikunda SK et al, (2003). The contribution of megacities to regional sulfur pollution in Asia. Atmos Environ 2003;37(1):11-22.

Hanif, I. (2017). Economics-energy-environment nexus in Latin America and the Caribbean. Energy, $141,170-178$.

Hanif, I.(2018). Energy consumption habits and human health nexus in Sub-Saharan Africa. Environ Sci Pollut Control Ser, 1-12.

Hanif, I. (2018a). Impact of fossil fuels energy consumption, energy policies, and urban sprawl on carbon emissions in East Asia and the Pacific: a panel investigation. Energy Strategy Rev, 21, $16-24$

Hanif, I. \& Gago-de-Santos, P. (2017). The importance of population control and macroeconomic stability to Reducing environmental degradation: an empirical test of the environmental Kuznets curve for developing countries. Environ Dev, 23(3),1-9.

Hanif, I., Aziz, B.\& Chaudhry, I.S. (2019a). Carbon emissions across the spectrum of renewable and nonrenewable energy use in developing economies of Asia. Renew Energy, 143, 586-595

Hanif, I., Raza, S.M.F., Gago-de-Santos, P. \& Abbas, Q. (2019b). Fossil fuels, foreign direct 
investment, and economic growth have triggered $\mathrm{CO} 2$ emissions in emerging Asian economies: some empirical evidence. Energy, 171, 493-501

Heidari, H., Katircio_glu, S.T. \& Saeidpour, L.(2015). Economic growth, CO2 emissions, and energy consumption in the five ASEAN countries. Int J Electr Power Energy Syst, 64, 785-791.

He, J.(2006). Pollution haven hypothesis and environmental impacts of foreign direct investment: the case of industrial emission of sulfur dioxide (SO2) in Chinese provinces. Ecol Econ , 60(1), 228245.

Henderson, D.J. \& Millimet, D.L.(2007). Pollution abatement costs and foreign direct investment inflows to the US states: a nonparametric reassessment. Rev Econ Stat ,89(1),178-183.

IPCC. (2007). Climate change 2007-mitigation of climate change. Contribution of working group III to the fourth assessment report of the Intergovernmental Panel on Climate Change. Retrieved September 2018, from https://www.ipcc.ch/site/assets/uploads/2018/03/ar4_wg2_full_report.pdf.

Kais S, Sami H. An econometric study of the impact of economic growth and energy use on carbon emissions: panel data evidence from fifty-eight countries. Renew Sustain Energy Rev 2016;59:1101e10.

Kuznets S. Economic growth and income inequality. Am Econ Rev 1955;45(1): 1e28.

Kao, C. (1999). Spurious regression and residual-based tests for cointegration in panel data. Journal of Econometrics,90(1), 1-44.

Lau, L.S., Choong, C.K. \& Eng, Y.K.(2014). Investigation of the environmental Kuznets curve for carbon emissions in Malaysia: do foreign direct investment and trade matter? Energy Policy, 68, 490-507.

Lee, S. \& Oh, D.W.(2015). Economic growth and the environment in China: empirical evidence using prefecture-level data. China Econ Rev, 36, 73-85.

Levin, A., C.F. Lin and C.S.J. Chu (2002) "Unit root tests in panel data: asymptotic and finitesample properties", Journal of Econometrics, 108, 1-24.

Maranga, E., Mugabe, P. H., \& Bagine, R. K. (2010). Concepts, theories and principles of natural resources management. In W. D. Ochola, P. C. Sanginga, \& I. Bekalo (Eds.), Managing Natural Resources for Development in Africa: A Resource Book. Ottawa: IDRC.

Menyah, K. \& Wolde-Rufael, Y.(2010). CO2 emissions, nuclear energy, renewable energy and economic growth in the US. Energy Policy, 38(6).

N. Apergis, I. Ozturk, Testing environmental Kuznets curve hypothesis in Asian countries, Ecol. Indicat. 52 (2015) 16e22.

Pedroni, P. (2004). Panel cointegration: asymptotic and finite sample properties of pooled time series tests with an application to the PPP hypothesis. Econometric theory, 20(3), 597625.

Perman, R., \& Stern, D. I. (2003). Evidence from panel unit root and cointegration tests that the environmental Kuznets curve does not exist. Australian Journal of Agricultural and Resource Economics, 47(3), 325-347.

Pesaran MH, Shin Y, Smith RJ. Bounds testing approaches to the analysis of level relationships. J Appl Econom 2001;16(3):289e326.

S. Nasreen, S. Anwar, I. Ozturk, Financial stability, energy consumption and environmental quality: evidence from South Asian economies, Renew. Sustain. Energy Rev. 67 (2017) 1105e1122.

Saboori, B. \& Sulaiman, J.(2013). CO2 emissions, energy consumption and economic growth in Association of Southeast Asian Nations (ASEAN) countries: a cointegration approach. Energy,55, 813-822.

Sadorsky, P. (2014). The effect of urbanization on CO2 emissions in emerging economies. Energy Econ, 41,147-153.

Shahbaz, M., Loganathan, N., Muzaffar, A.T., Ahmed, K. \& Jabran, M.A. (2016). How urbanization affects $\mathrm{CO}_{2}$ emissions in Malaysia? The application of STIRPAT model. Renew Sustain Energy Rev, 57, 83-93. 
Shahbaz, M., Tiwari, A.K. \& Nasir, M.(2013). The effects of financial development, economic growth, coal consumption and trade openness on $\mathrm{CO}_{2}$ emissions in South Africa. Energy Policy, 61, 1452-1459.

Sharma, S.S. (2011). Determinants of carbon dioxide emissions: empirical evidence from 69 countries. Appl. Energy, 88(1), 376-82.

Shrestha, R.M., Anandarajah, G. \&Liyanage, M.H.(2009). Factors affecting $\mathrm{CO}_{2}$ emission from the power sector of selected countries in Asia and the Pacific. Energy Policy, 37(6), 2375-2384.

Smurti and Dash (2017). The effect of urbanization, energy consumption, and foreign direct investment on the carbon dioxide emission in the SSEA (South and Southeast Asian) region. Renew Energy 70 (2017), 96-106.

Wang P, Wu W, Zhu B, Wei Y. Examining the impact factors of energy-related $\mathrm{CO} 2$ emissions using the STIRPAT model in Guangdong Province, China. Appl Energy 2013;106:65e71.

Zarsky, L.(1999). Havens, halos and spaghetti: untangling the evidence about foreign direct investment and the environment. Foreign Dir. Invest. Environ.,13(8), 47- 74.

Zhang L, Gao J. Exploring the effects of international tourism on China's economic growth, energy consumption and environmental pollution: evidence from a regional panel analysis. Renew Sustain Energy Rev 2016;53: 225e34.

Ziaei SM. Effects of financial development indicators on energy consumption and CO2 emission of European, East Asian and Oceania countries. Renew Sustain Energy Rev 2015;42:752e9. 